\title{
The Effect of Vibration on Muscle Activity and Grip Strength using an Electric drill
}

\author{
M. Widia, S.Z.Dawal \\ Department of Mechanical Enigeering, \\ University of Malaya, \\ Lembah Pantai, \\ Kuala Lumpur, 50603, Malaysia \\ it4_m2m@yahoo.co.id, zawimd@yahoo.co.uk
}

Keywords : Electric Drill, Vibration Level, Muscle Activity and Grip Strength

\begin{abstract}
The paper focused on the effects of vibration exposure on muscle activity and grip strength. The study was conducted on eighteen subjects, required to drill wood material using electric drill for 5 and 15 minutes. Electromyography (EMG), Vernier Labpro with 3 axis accelerometer and hand dynamometer were used in the experiment. The results showed that right extensor carpi radialis muscle had the highest percentage of Maximum Voluntary Contraction (MVC) with values of 21.8\%MVC- $23.5 \%$ MVC. The mean vibration level was $10.45 \mathrm{~m} / \mathrm{s}^{2}$ (5 minutes) and $10.69 \mathrm{~m} / \mathrm{s}^{2}(15$ minutes). Drilling wood material for 15 minutes resulted in higher percentage MVC (7.79\%), vibration levels $(2.29 \%)$, and percentage decrease ratio $(11.17 \%)$ than using 5 minutes for the extensor carpi radialis muscle. The findings of the study indicated that as the level of vibration and exposure duration increase the muscular activity and the percentage decrease ratio of grip strength would also increase.
\end{abstract}

\section{INTRODUCTION}

Vibration is transmitted to body by physical contact with vibrating tools or handheld powered tools used in manufacturing, construction, forestry, and others [1]. The effects of vibration has been known for many years which causes illness to operators or someone using the vibrating tools or hand held power tools. Using powered hand tools instead of man-powered hand tools, although increasing productivity, has also increased the risk of musculoskeletal injuries and diseases due to a more rapid pace, heavier tool weight, and greater tool vibration [2].

Previous research has little information on how vibration is related to muscle disorder. They do not emphasize on upper limb muscles and only concluded vibration level as significant factors to muscle disorder compare to other factors such as feed force.

Therefore, in order to quantify and assess safe levels of human exposure to vibration, it is necessary to measure and analyze the characteristics of vibrations and their effect of on muscle activity and grip strength. Thus, the objective of this paper are to investigate the characteristics of vibration factors (vibration level and exposure duration) produced by vibrating tools that affect to muscle activity and to analyze the effects of vibration exposure on muscle activity and grip strength.

\section{METHODOLOGY}

\subsection{Subject}

Eighteen healthy volunteers, nine males and nine females, participated in the study. The subjects have no experience any history or previous injury in shoulder or arm. The subjects were between the ages of 22 and 38 to match the age range of the target working population. Height and weight of each subject were measured. All subjects were thoroughly informed of the experimental procedure and gave consent prior to participation. 


\subsection{Experimental Design}

Each subject was required to drill the wood under two different exposure duration ( 5 minutes and 15 minutes). The size of the work piece is $10 \times 10 \mathrm{~cm}$. Thickness of the work piece is $3 \mathrm{~cm}$. Each subject was asked to drill the work piece using a $1.5 \mathrm{~kg}$ electric drill (Bosch GBM $450 \mathrm{RE}$ Professional Rotary Drill) was fitted with a steel rod bit $7.3 \mathrm{~cm}$ long and $0.4 \mathrm{~cm}$ in diameter. Subjects were required to perform the drilling task in an upright standing position. Subjects were given a minimum 15 minutes rest after each experiment. There were two experiments taken for each subject using equipments to drill wood materials for two different duration periods.

\subsection{Experiment Apparatus}

\subsubsection{Drilling machine}

The portable drilling machine (Bosch GBM $450 \mathrm{RE}$, approx. weight $1.5 \mathrm{~kg}, \varnothing 4 \mathrm{~mm}, 450 \mathrm{~W}$ ) was used in this study. The tool was in good working condition.

\subsubsection{Noraxon EMG and Sensor system}

EMG (Noraxon. Myoresearch XP, Basic Edition V.1.06.69) with sampling rate $1000 \mathrm{~Hz}$ was used to measure muscle activity during drilling.

\subsubsection{Vernier Labpro with 3 axis accelerometer}

Vernier Labpro with 3 axis accelerometer (3D-BTA ${ }^{1}$ ) was used to measure vibration level create during drilling task of wood material.

\subsubsection{Hand Dynamometer}

Vernier Labpro with hand dynamometer was used to measure grip strength of subjects before and after the drilling tasks of each duration. Using the appropriate data collection hardware and software, the dynamometer was used to plot the graph, recorded, calculated, and compared hand grip muscle fatigue rates.

\subsection{Experimental Procedure}

\subsubsection{Vibration level measurement}

The equipment for measuring vibration acceleration intensity was vernier labpro with tri axis accelerometer. Vibration was measured at locations on the tool in closest contact with the hands by mounting accelerometers directly to the handles. Vibration was measured in three orthogonal coordinate axes in accordance with the ISO 5349 hand and arm basicentric coordinate system $[1,3,4]$.

\subsubsection{Muscle Activity measurement (\% MVC)}

Electromyography was used to determine the level of strain created in the muscles by repetitive movement of hand arm shoulder system. Surface EMG electrodes pick up the electrical activity of superficial muscles and the amplitude and power spectrum of the signals can be determined [5]. The amplitude reflects the number and size of action potential in the muscle over a given period [5].

\subsubsection{Grip Strength Measurement}

Strength evaluation is important when there is a need to match a worker's capacity to the demands of the task. Such knowledge will help to reduce musculoskeletal disorders as a result of physical mismatch. Grip Strength is tested by holding the sensor in a vertical position, with the arm perpendicular to the body and the fingers on the pad distal to the longer proximal portion on which the palm is pressed. Strength can be measured by applying pressure for a series of short grasps or over a sustained duration.

\section{RESULTS}

\subsection{Objective Measurement}

\subsubsection{Muscle Activity}

Right extensor carpi radialis is the most affected muscle with $23.5 \% \mathrm{MVC}$ for 15 minutes and $21.8 \% \mathrm{MVC}$ for 5 minutes. The majority of muscles reacted and the $\% \mathrm{MVC}$ as follow: right biceps brachii $5.25 \%$ for 5 minutes and $5.35 \%$ for 15 minutes and right upper trapezius p.descendez 
$11.05 \%$ for 5 minutes and $11.77 \%$ for 15 minutes. No significant differences were found between the experiments for the extensor carpi radialis, biceps brachii and trapezius pars descendens muscles.

\subsubsection{Vibration Level}

The results show the highest mean RMS value of vibration is $10.69 \mathrm{~m} / \mathrm{s}^{2}$ during the 15 minutes electric drill task. The results indicated that 15 minutes exposure duration give higher vibration level $(2.29 \%)$ than those 5 minutes, however the paired t-test result didn't show significant difference.

\subsubsection{Grip Strength}

The highest percentage decrease in grip strength was drilling using an electric drill for 15 minutes $(29.23 \mathrm{~N})$.

A set of paired T-tests was performed to compare the grip strength values before and after the experiment for all subjects with the $p$ value set at 0.05 . Table III-IV indicates that grip strength values $(p=0.0356$ and $p=0.0001)$ before and after the experiment were significantly different $(p<0.05)$.

\section{DISCUSSIONS}

\subsection{Muscle Activity}

The effect of hand-held vibrating tools on significant muscle was analyzed. The experiment demonstrated the effect of vibration on muscles of the arm and shoulder system. Vibration was transmitted from a handle to the arm and shoulder in an upright standing posture and affected the muscles.

Three types of muscles were investigated in this research. Extensor carpi radialis, Biceps brachii and Trapezius pars descendensz. These three muscles were specifically targeted because the literature review showed that these are the main muscles used when an operator is exposed to vibration. In addition, they are prominent and easily accessible for surface EMG placement.

The right extensor carpi radialis showed the greatest increase in the \% MVC $(23.50 \% \mathrm{MVC})$ value in all experiments. The extensor carpi radialis is one of the muscles in the lower arm and one of the five main muscles that control movements at the wrist. This muscle is an extensor at the wrist joint, which manipulates the wrist so as to move the hand towards the thumb. According to some studies [6], the muscles of the hand adjacent to the base of the thumb may be the most affected. Radwin et. al (1987)[7] also found that EMG increased 32\% for lower arm extensors in the lower arm when gripping a handle with vibration compared with one without vibration. These findings showed that the lower arm is the most affected compared to other parts of the arm. As the muscle tension increases, there is an increase in myoelectric activity [7].

We also found the greatest increase of \% MVC (11.05 and $11.77 \% \mathrm{MVC})$ value in trapezius pars descendenz. It can probably be explained by the fact that the trapezius pars descendenz muscle is sensitive to changes in working posture and responds with increased muscle activity when the hand is exposed to vibration. The different parameters of vibration influence the transmission of vibrations in the human body, and work-related factors such as gripping, pushing force and posture $[6,8,9]$.

Biceps muscle activity showed the lowest \% of MVC (4.20 and $4.60 \% \mathrm{MVC})$. This can be explained by the fact that it is not a prime mover in pushing the drill. The length of the bicep muscle for the posture is shorter relative to the other muscles. Since it is known that the initial muscle length and the degree of muscle contraction facilitates the tonic vibration reflex (TVR), it is reasonable to assume that the biceps muscle is not a prime mover in pushing and is, therefore, not affected greatly by vibration.

Several investigators have recommended average force exposure limits for preventing fatigue. These limits are range from $0 \%$ to $15 \%$ maximum voluntary contraction (\%MVC) for continuous exertions and from $15 \%$ to $21 \%$ for intermittent exertions [10-12]. The muscle activity value for 
drilling using a electric drill was highest in the right extensor carpi radialis muscle (21.8043-23.50 $\% \mathrm{MVC}$ ). The mean \%MVC for right extensor carpi radialis muscles was higher than those values in the guidelines for intermittent work specified by some researchers. This result indicates that drilling using an electric drill may be associated with high levels of hand activity.

\subsection{Vibration Level and Exposure Duration}

The result showed that the mean vibration level during drilling using a electric drill for 15 minutes was the highest value compared to the other conditions $\left(10.69 \mathrm{~m} / \mathrm{s}^{2}\right)$. This indicates that vibration level increase as the exposure duration increase. The percentage differences in vibration levels for drilling using the electric drill for 15 minutes and 5 minutes was $2.24 \%$. This result is in line with Dawal et. al (2008)[13], who also found that the increasing of vibration levels while performing a manual drilling task increased the heart rate and RMS value. Forceful exertions may result in increased vibration transfer to the tool operator's hand and arm because of increased coupling between the vibrating handle and the hand. Highly repetitive work can affect vibration exposure by increasing accumulated does of repeated exposures to vibration. These interactions have certainly complicated the study of ergonomic stress factors and their combined effects with hand transmitted vibration [7].

Another variable investigated in this study was duration of exposure. The durations of exposure was used in this experiment were 5 and 15 minutes. There is substantial evidence that as the intensity and duration of exposure to vibrating tools increase, the risk of developing HAVS increases. NIOSH (1989) [14] stated that the components of the hand-transmitted vibration to be measured were (a) acceleration $\left(\mathrm{m} / \mathrm{s}^{2}\right)$, (b) frequency $(\mathrm{Hz})$ and (c) duration of exposure (min/day or $\mathrm{hr} /$ day). Previous researches studies have shown that problems associated with exposure to occupational hand-arm vibration increased with the continued exposure to vibration ([15], [16], [17]). Nagata et. al. (1993) [18] established a dose-response relationship between the prevalence of Raynaud's phenomenon and duration of exposure to vibration. These authors found an increase in the odds ratio of Raynaud's phenomenon in groups with long term vibration exposure. Even if the vibration duration was short, there were significant effects when subjects were exposed to a vibration level of $3.5 \mathrm{~m} / \mathrm{s}^{2}$ [19]. Vibration generating acceleration of $1 \mathrm{~m} / \mathrm{s}^{2}$ has been considered by some researchers as the threshold level below which no noticeable adverse effects would be observed in workers [20].

According to NIOSH (1989) [14], data on the vibration acceleration level produced by vibrating tools is needed for the design of tools and work strategies that will help to prevent and control HAVS at the earliest possible stage. There are limited published data on vibration exposure to handheld vibrating tools especially in Malaysian industries. The result of this study about vibration levels of electric drills can be used as guidelines by employees and employers in manufacturing fields, as well as by manufacturers that produce this kind of drill to improve the design of electric drill to be more ergonomic. It can be concluded that the study proven the hypothesis: vibration level (acceleration) and exposure duration as factors that influences the effect of vibration on the hand.

\subsection{Grip Strength}

Strength is the capacity of a muscle to exert maximal effort or resist maximal opposing force. Experiments have shown that drilling using a electric drill for 15 minutes produce a $29.23 \%$ larger decrease in grip strength whereas using electric drill for 5 minutes results in only a $24.50 \%$ decrease. Paired t-test result also showed significant differences between grip strength before and after experiment for all experiments.

This difference might be due to vibration level for 15 minutes being larger than 5 minutes; thus, the subject needs to apply excess force to grip the electric tool and maintain stability in performing drilling tasks for longer time. This finding is also supported by Radwin et. al (1987) [6], who showed that a higher grip force is often applied to vibration tools to maintain stability in performing prolonged tasks. This condition makes the subjects lose some of grip strength after the experiments.

Decreased grip strength is a sign of musculoskeletal disorders (MSDs). The percentage decrease in grip strength also increases as the vibration level and exposure duration is increased. This result 
supports the statement of NIOSH (1989) [14] that reductions in grip strength increased in number and severity as the exposure to vibrations (acceleration intensity and duration of exposure) increased.

\section{CONCLUSIONS}

Based on our findings, we conclude that:

1. The result showed strong relationships between muscle activity, grip strength, interval time and vibration level. Muscle activity and ratio decrease of grip strength increase as the vibration level and exposure duration increase.

2. Drilling using electric drill for 5 and 15 minutes caused the right extensor carpi radialis muscle to record maximum \%MVCs of $21.8 \% \mathrm{MVC}$ and $23.5 \% \mathrm{MVC}$, respectively, and the reductions in grip strength increased in number and severity as the exposure to vibration (vibration level and duration of exposure) increased.

3. Vibration levels produced during drilling for 5 and 15 minutes with the electric drill were 10.45 $\mathrm{m} / \mathrm{s}^{2}$ and $10.69 \mathrm{~m} / \mathrm{s}^{2}$, respectively.

4. Subjective measurement results supported objective measurement results indicated that the upper and lower arm as the most affected by hand-held vibrating tools compared to other body parts.

\section{ACKNOWLEDGMENT}

This work is financially supported by the Ministry of Higher Education Malaysia under the High Impact Research Grant UM.C/HIR/MOHE/ENG/35 (D000035-16001).

\section{REFERENCES}

[1] Occupational Safety and Health Malaysia. Guidelines on Occupational Vibration. Department of Occupational Safety and Health Ministry of Human Resources Malaysia. 2003.

[2] Chang, C and Wang, M. J. Evaluating factors that influence hand-arm stress while operating an electric screwdriver. Applied ergonomics 2000:31:283-289.

[3] Vergara, M., Sancho, J.L., Rodríguez, P., and González, A.P. Hand-transmitted vibration in power tools: Accomplishment of standards and users' perception. International Journal of Industrial Ergonomics 2008:38: 652-660.

[4] Milosevic, M. and McConville, K.M.V.. Measurement of Vibrations and Evaluation of Protective Gloves for Work with Hand-held Tools in Industrial Settings. Proceedings of the $29^{\text {th }}$ Annual International Conference of the IEEE. EMBS Cite Internationale, Lyon, France, 2007.

[5] Venkata, B.K.B.. Effect of Overhead Drilling support on Muscular Activity of Shoulder. Agricultural and Mechanical College, Lousiana State University, 2006.

[6] Radwin, R.G., Armstrong, T.J., Chaffin, D.B. Power hand tool vibration effects on grip exertions. Ergonomics 1987:30:(5), 833-855.

[7] Rohmert, W., Wos, H., Norlanderand. S., Helbig. R. Effects of Vibration on arm and Shoulder Muscles in Three Body Postures. Eur J Appl Physiol 1989:59:243-248.

[8] Zadry H. R, Dawal, S. Z, Taha, Z. Investigation of Upper limb Muscle Activity during Repetitive Light Tasks using Surface Electromyography (SEMG). Proceeding of 2009 IEEE Toronto International Conference-Science and Technology for Humanity.Toronto,Canada, 2009.

[9] Bystrom, S.E., and Kilbom, A. Physiological response in the forearm during and after isometric intermittent handgrip. Eur. J. Appl. Physiol. Occup. Physiol 1990:60:457-466. 
[10] Bystrom, S., and Fransson-Hall, C., Acceptability of intermittent handgrip contractions based on physiological response. Hum Factors 1994:36:158-171.

[11] Bjorksten, M, and Jonsson, B. Endurance limit of force in long-term intermittent static contractions. Scandinavian Journal of Work Environment and Health 1997:3:23-27.

[12] SjøGaard, G., Kiens, B., Jorgensen, K., Saltin, B. (1986). A muscular pressure, EMG, and blood flow during low-levelprolonged static contraction in man. Acta Physiologica Scandinavica 1986:128:475-484.

[13] Dawal, S.Z., Mirta, W., Ling, Y.H., and Zadry, H. R. The Effect of Electric Drill Laboratory Hand Tool on Muscle Activity and Heart Rate Measurement. IFMBE Proceedings, 4th Kuala Lumpur International Conference on Biomedical Engineering. ISSN 2008:1680-0737. Volume 21.

[14] NIOSH. Criteria for a Recommended Standard: Occupational Exposure to Hand-Arm Vibration. 1989. Cincinnati.

[15] Dong, R.G., Schopper, A.W., McDowell, T.W., Welcome, D.E., Wu, J.Z., Smutz, W.P., Warren, C., Rakheja, S. Vibration energy absorption (VEA) in humanfingers-hand-arm system. Medical Engineering \& Physics 2004:26:483-492.

[16] Petersen, R., Andersen, M., Mikkelsen, S., Nielsen, S.L. (1995). Prognosis of vibration induced white finger: a follow up study. Occup Environ Med 1995:52:110-115.

[17] Pyykko, I., Korhonen, O., Farkkila, M., Starck, J., Aatola, S., Jantti, V. Vibration syndrome among Finnish forest workers, a follow-up from 1972 to 1983. Scand. J. Work. Environ. Health 1986:12:307-312.

[18] Nagata, C., Yoshida, H., Mirbod, S.M., Komura, Y., Fujita, S., Inaba, R., Iwata, H., Maeda, M., Shikano, Y. and Mori, S. Cutaneous signs (Raynaud's phenomenon, sclerodactylia, and edema of the hands) and hand-arm vibration syndrome. International Archives of Occupational and Environmental Health 1993:64:587-591.

[19] Barregard, L., Ehrenstrom and Marcus, K. Hand-arm vibration syndrome in Swedish car mechanics. Occup. Environ. Med. 2003:60:287-294.

[20] Taylor, W., Brammer, A.Vibration Effects on the Hand and Arm in Industry: An Introduction and Review. Wiley, New York. 1982. 